\title{
Estimation of antioxidant components of tomato using VIS-NIR reflectance data by handheld portable spectrometer**
}

\author{
Péter Szuvandzsiev ${ }^{1}$, Lajos Helyes ${ }^{1}$, Andrea Lugasi ${ }^{2}$, Csongor Szántó ${ }^{1}$, Piotr Baranowski ${ }^{*}$, and Zoltán Pék ${ }^{1}$ \\ ${ }^{1}$ Institute of Horticulture, Szent István University, Páter K. út 1., H-2100 Gödöllő, Hungary \\ ${ }^{2}$ Department of Catering, Budapest Business School, College of Commerce, Catering and Tourism, \\ Alkotmány u. 9-11, H-1054, Budapest, Hungary \\ ${ }^{3}$ Institute of Agrophysics, Polish Academy of Sciences, Doświadczalna 4, 20-290 Lublin, Poland
}

Received March 6, 2014; accepted July 2, 2014

\begin{abstract}
A b s t r a c t. Processing tomato production represents an important part of the total production of processed vegetables in the world. The quality characteristics of processing tomato, important for the food industry, are soluble solids content and antioxidant content (such as lycopene and polyphenols) of the fruit. Analytical quantification of these components is destructive, time and labour consuming. That is why researchers try to develop a non-destructive and rapid method to assess those quality parameters. The present study reports the suitability of a portable handheld visible near infrared spectrometer to predict soluble solids, lycopene and polyphenol content of tomato fruit puree. Spectral ranges of 500-1000 nm were directly acquired on fruit puree of five different tomato varieties using a FieldSpec HandHeld 2 ${ }^{\text {TM }}$ Portable Spectroradiometer. Immediately after spectral measurement, each fruit sample was analysed to determine soluble solids, lycopene and polyphenol content. Partial least square regressions were carried out to create models of prediction between spectral data and the values obtained from the analytical results. The accuracy of the predictions was analysed according to the coefficient of determination value $\left(\mathrm{R}^{2}\right)$, the root mean square error of calibration/ cross-validation.
\end{abstract}

K e y w o r d s: tomato, VIS NIR reflectance, SSC, lycopene, polyphenols

\section{INTRODUCTION}

Tomato (Lycopersicon esculentum Mill.) is one of the most important vegetable food crops of the world (FAOSTAT, 2014). The significance of processing tomato products is characterized by their high consumption, year-round availability and health benefits, due to their antioxidant content, in the prevention of non-communicable

*Corresponding author e-mail: pbaranow@ipan.lublin.pl

**This study was partly financed by TÁMOP-4.2.1. B-11/2/ KMR 2011-0003 and Research Centre of Excellence 175864/2013/TUDPOL) Szent István University and KTIA AIK 121-2012-0012 project. diseases, and points to a role for plant-derived phytochemicals in the prevention of heart disease and cancer (WHO, 1990).

Processing tomato has a determinate growth habit, bush-like canopy and is only cultivated under open field production conditions. Economically and technologically the most important quality characteristic and the major goal of breeding programs is high soluble solids content (SSC) (Grandillo et al., 1999), because of its strong negative correlation with the energy cost for dehydration during the processing (Singh et al., 1980). SSC is a refractometric index which specifies the percentage of a given substance, in this case dissolved solid constituents, and it is measured in ${ }^{\circ}$ Brix. More than half of tomato fruit SSC is given by sugars and acids, additionally it is a representative indicator of phenols, amino acids, soluble pectin, citric acid, minerals and phytonutrients (Beckles, 2012; Helyes et al., 2006). The main phytonutrients are carotenoids and polyphenols such as antioxidants which are important nutritional benefits of tomato, due to their positive influence in the prevention of cardiovascular, bone, and gastrointestinal diseases in the human body (Bolca et al., 2013; Lugasi et al., 2004). Lycopene, the main carotenoid of tomato fruit, is often considered a major factor for cardiovascular protection in addition to its importance in the reduction of oxidative stress active substance (Abete et al., 2013). Concentration of lycopene is not homogeneous inside fruits of traditional processing tomatoes, being the highest in the peel, lower in the fruit wall and placenta and the lowest in the seed (Toor and Savage, 2005).

(C) 2014 Institute of Agrophysics, Polish Academy of Sciences 
The total quantity of flavonoids and phenolic acids is often considered as an important quality index of processing tomato (Pék et al., 2014). The beneficial influence of polyphenols came to light when vitamin $\mathrm{C}$ was discovered (Figueirinha et al., 2008). In relation to epidemiological examinations, it is certain that they provide a high efficiency preventive function of the human body. In addition, this active ingredient group carries the possibility of functional food (Canene-Adams et al., 2005).

Analytical quantification of these components is destructive, time and labour consuming. That is why researchers try to develop a non-destructive and rapid method to assess the fruit quality. Visible and near infrared (VIS NIR) spectroscopy testing has the ability to estimate active ingredient content of tomato. This technology is high precision, time saving and non-destructive, which could help the determination of optimal harvesting date and high quality (Xie et al., 2008; Ecarnot et al., 2013). There is also evidence that spectral properties in mid-infrared $(8-13 \mu \mathrm{m})$ are strongly correlated with mechanical properties of tomato skin (Gładyszewska et al., 2011).

Recent articles frequently analyse the spectral data in the context of dry matter content. This definition is cheap and quite closely related to the more expensively defined phytonutrients. Therefore, we tried to test the methodology for lycopene and polyphenols, the two most physiologically important antioxidant components of tomato. The present study reports the suitability of a portable handheld VIS-NIR spectrometer to predict SSC, lycopene and polyphenol content of tomato fruit puree.

\section{MATERIALS AND METHODS}

Fruits were produced in an open field experiment of processing tomato in 2012. This experiment was conducted at the Experimental Farm of the Institute of Horticulture at Szent István University $\left(47^{\circ} 35^{\prime} \mathrm{N}\right.$. 19 $\left.21^{\circ} \mathrm{E}\right)$, Gödöllö, Hungary. Growing technology was the same as our previous processing tomato experiment (Helyes et al., 2012). Five different processing tomato hybrids were planted out: Heinz $9663 \mathrm{~F}_{1}(\mathrm{H})$, Triple red $\mathrm{F}_{1}(\mathrm{TR})$, Ug red $\mathrm{F}_{1}$ (UGR), Uno Rosso $F_{1}$ (UR) and Trombolino $F_{1}(S T)$. Irrigation was applied by drip irrigation in three treatments: optimum water supply $100,75,50 \%$ water supply $100,75,50$, respectively, versus rain-fed (K) crops. Optimum water supply was calculated from daily potential evapotranspiration of tomato (Pék et al., 2014), based on weather forecast data of the Hungarian Meteorological Service. The availability of water usable for plants was 596, 502, 404 and 219 $\mathrm{mm}$, respectively, in the treatments during the vegetative period. Seedlings were additionally treated with Symbivit ${ }^{\circledR}$ (M) arbuscular mycorrhizal fungi (natural plant growth enhancer), at the rate of $25 \mathrm{~g} /$ seedling, only in the optimum water supply treatments at planting out. So the following variety/treatment combinations were harvested: UR K, UR
50, UR 75, UR 100, UR 100 M, H 100, H 100 M, TR K, TR 50, TR 75, TR 100, TR 100 M, UGR 100, ST K, ST 100 and ST $100 \mathrm{M}$ (Table 1). We did not carry out all combinations of treatments, because of the given capacity of the experimental farm. Five fruits and four repetitions in each treatment were harvested by hand in red ripe stage on 14th of August, 2012.

Spectral and analytical measurements were performed on tomato samples just after harvesting. The fruits were washed, cut and mixed, and 64 puree samples were used for analysis. Spectral ranges of 325-1075 nm were directly acquired on five different tomato varieties using a FieldSpec HandHeld 2 ${ }^{\mathrm{TM}}$ (Analytical Spectral Devices Inc., Co. USA) Portable Spectroradiometer. A black teflon plate (diameter $75 \mathrm{~mm}$ ) was filled with $26 \pm 1 \mathrm{~mm}$ of samples. Spectral measurements were taken with the instrument positioned $20 \mathrm{~mm}$ above the samples, with Hi-Brite Contact Probe. The instrument has spectral resolution of $<3.0 \mathrm{~nm}$ at $700 \mathrm{~nm}$ and the wavelength accuracy of $\pm 1 \mathrm{~nm}$.

T a b l e 1. Average value of tomato fruits components from different varieties/treatment combinations $(n=4)$

\begin{tabular}{lccc}
\hline $\begin{array}{l}\text { Varieties/ } \\
\text { treatment }\end{array}$ & SSC & Polyphenol & Lycopene \\
\hline UR K & 7.18 & 70.75 & 11.93 \\
UR 50 & 6.13 & 60.85 & 9.98 \\
UR 75 & 5.93 & 55.25 & 9.38 \\
UR 100 & 5.20 & 50.38 & 9.40 \\
UR 100 M & 5.33 & 56.55 & 8.03 \\
H 100 & 5.65 & 56.15 & 8.65 \\
H 100 M & 5.69 & 54.98 & 12.75 \\
TR K & 9.60 & 83.35 & 18.00 \\
TR 50 & 7.65 & 68.75 & 13.03 \\
TR 75 & 7.16 & 73.03 & 10.25 \\
TR 100 & 6.75 & 79.90 & 10.78 \\
TR 100 M & 6.73 & 71.33 & 9.18 \\
UGR 100 & 5.70 & 54.05 & 8.93 \\
ST K & 7.55 & 100.65 & 25.15 \\
ST 100 & 6.28 & 87.73 & 14.65 \\
ST 100 M & 6.83 & 91.13 & 18.78 \\
Range & $5.0-10.0$ & $46.1-110.2$ & 7.0 \\
Mean & 7.60 & 69.70 & 26.30 \\
SD & 0.28 & 3.93 & 1.17 \\
\hline & & & \\
\hline
\end{tabular}


Immediately after spectral measurement, each fruit sample was analysed to determine soluble solids, lycopene and other antioxidant content. The soluble solid content (SSC) value was measured using a digital refractometer KRÜSS DR201-95 (A.KRÜSS Optronic, Hamburg, Germany) with accuracy of $\pm 0.2^{\circ}$ Brix.

Lycopene from homogenised tomatoes was extracted with an n-hexane-methanol-acetone (2:1:1) mixture containing $0.05 \%$ BHT. Water-free $\mathrm{Na}_{2} \mathrm{SO}_{4}$ was used to remove water traces from the upper part. The optical density of the hexane extract was measured spectrophotometrically at $500 \mathrm{~nm}$ against a hexane blank (Sadler et al., 1990) with a UV-VIS Spectrophotometer Lambda 3B (PerkinElmer). The concentration of lycopene was calculated using a specific extinction coefficient $\left(\mathrm{E}_{1 \mathrm{~cm}} 1 \%\right.$ 3150) (Merck, 1989).

The determination of total polyphenols content was performed spectrophotometrically according to the FolinDenis method at $760 \mathrm{~nm}$ (AOAC, 1990).

For the multivariate analysis, partial least squares regression (PLSR) was carried out. The PLSR projects the variables into new orthogonal latent variables, by maximising the correlation between the explanatory and the explained variables.

PLSR is a commonly used multivariate regression method when there are few samples and several variables, and the data are multicollinear (Wold et al., 2001). When there is only one response variable, the method is referred to as PLS1, and the models are used to determine the linear relationship between the predictor ( $\mathrm{X}$ matrix) and the response ( $\mathrm{Y}$ vector) variables. The method uses latent variables (LV, also referred as PLS components, factors) that are linear combinations of the variables. The goal is to maximise the covariance between the factor scores and response variables by the least squares method, minimising the residuals (Andersson, 2009). The calibration models can be validated by the results of the prediction on a test set, or by cross-validation or both. One method of crossvalidation is leave-one-out cross-validation (LOO CV). During the LOO CV, many PLS regressions are carried out on subsamples, created by removing one sample every time. It is carried out till every individual sample is validated. It is applicable either for determining the optimal latent variables (factors) or for evaluation of the calibration model. The optimal number of factors is determined by the lowest predicted residual sum of squares (PRESS) value, after setting the maximum extractable components, considering the number of samples, variables and examining the factor loading. For evaluating the models' predictor abilities, the coefficient of determination $\left(\mathrm{R}^{2}\right)$ and the root mean squared errors of calibration and cross-validation (RMSEP/ RMSECV) are examined. The good models are those featuring $\mathrm{R}^{2}$ close to one and low RMSE value.

\section{RESULTS AND DISCUSSION}

For one sample five tomato berries were mashed, and there were 4 repeats per treatment. Therefore we could observe graphically for outliers among these repeats reflectance spectra, as used by Xie et al. (2008). Other outlier detection algorithms were not carried out, as there were some samples with outstanding concentration values, from the control group only (Table 1). It seemed to be more reliable to just select the few obvious outlier spectra among the repetitions that were caused by measurement errors. By this method, three outlier samples were selected from all of the measurements.

Figure 1 shows the average reflectance spectra of tomato puree from variety/treatment combinations. Intense absorption appeared under $560 \mathrm{~nm}$. Above $560 \mathrm{~nm}$, reflectance values became higher, the maximum reflectance was measured between 645 and $713 \mathrm{~nm}$, depending on sample. In the near infrared region there was a local absorption maximum at around $980 \mathrm{~nm}$. Treatments could be discriminated by the different average values of reflectance spectra. The values decreased in the order of $\mathrm{K}, 50,75,100$, while the order of 100 and $100 \mathrm{M}$ was alternated, depending on the variety.

For the measurements of mashed tomato reflectance spectra, the Hi-Brite Contact Probe accessory was applied, equipped with built-in tungsten halogen light source. Because of the summed effect of spectral power distribution, the sensor silicon array detector's sensitivity and the samples absorption, at the margins of the spectra, and at the high absorption bands there was serious signal-to-noise ratio deficiency, added to the standard noise of the equipment. Therefore, first of all the Savitzky-Golay filter was applied, with polynomial degree 1, on 11 data points. After the smoothing, adequate signal-to-noise ratio was determined between 530 and $1000 \mathrm{~nm}$. The Standard Normal Variate (SNV) and Multiplicative Scatter Correction (MSC) pre-processing techniques were carried out on the smoothed spectra. For the 1st derivative, Savitzky-Golay filter, with polynomial degree 1, was applied on 23 points, and the spectra were constricted to $550-975 \mathrm{~nm}$ (Fig. 2).

The 2nd derivative of the spectra were not analyzed because of the intensified noise of the spectra of very complex samples. After the reduction of the examined wavelengths, only the low reflectance bands and low signal-to-noise bands were removed.

PLSR with non-linear iterative partial least squares (NIPALS) algorithm was applied to the tomato sample spectra, pre-processed 4 ways each. The SSC, lycopene and polyphenol calibration models validation was executed by LOO CV. Since 3 samples were removed, 61 samples were left for the analysis, which was barely enough even for an eligible PLS regression, so a test set for prediction was not selected. The best models were selected by the lowest RMSECV, the numbers of factors were selected by the lowest PRESS values. After the assessment of the 

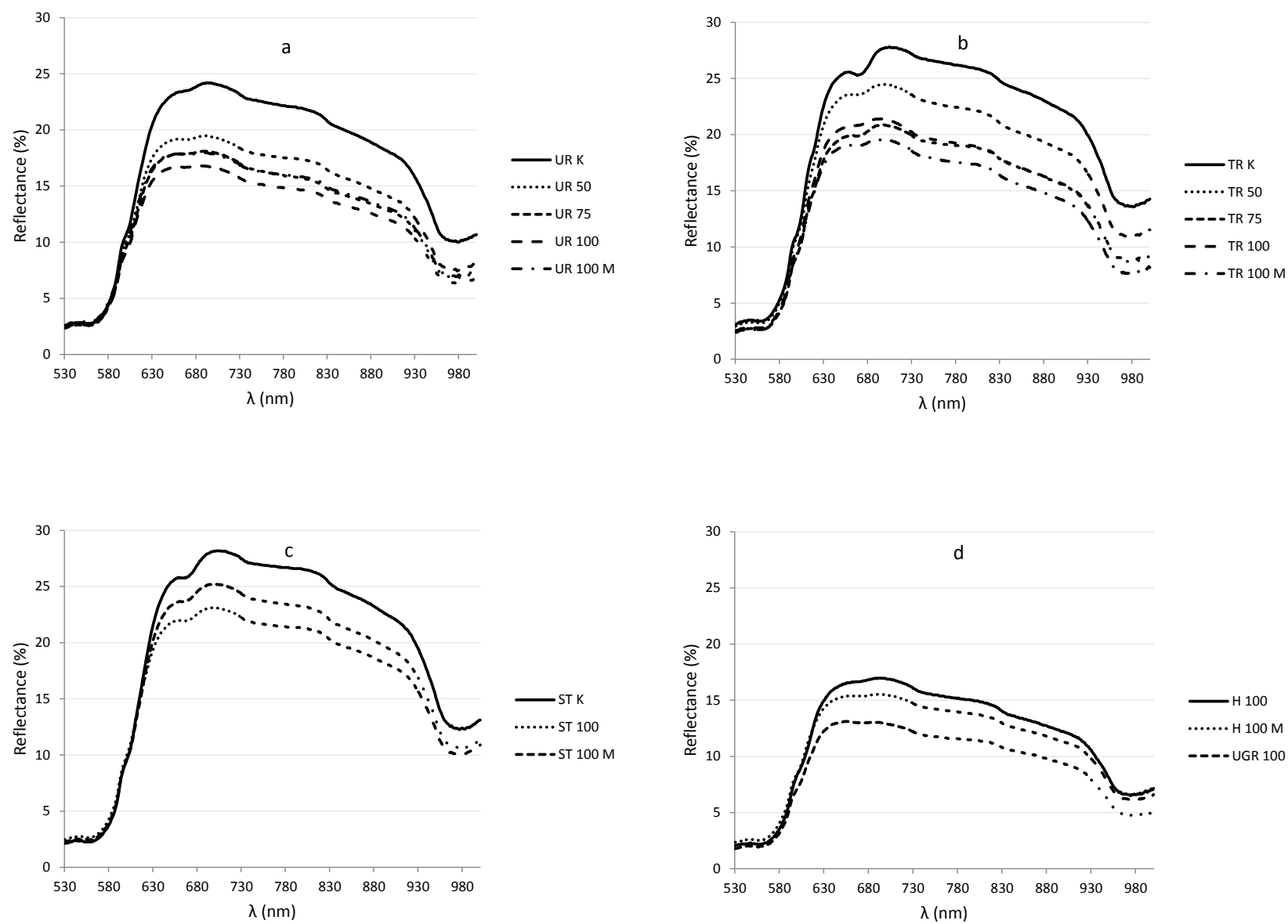

Fig. 1. Average VIS/NIR (530-1000 nm) raw reflectance spectra of tomato puree samples from different cultivar/treatment combinations ( $n=4)$ : $a-U R$ variants, $b-T R$ variants, $c-S T$ variants, $d-H$ and UGR variants.

SSC, lycopene and polyphenol calibration models, the 1st derivative of the spectra proved to be the best for each calibration model.

Our results are difficult to compare with other studies because of differences of spectroscopic methods, wavelength ranges, sample processing (whole tomato fruits, purees, juices) and varieties. Most of the studies were performed in a narrow region of the near-infrared, generally between 800 and $1100 \mathrm{~nm}$, which probably limits the development of applications providing sufficient predictive capacity for determining more complex quality parameters (Ecarnot et al., 2013; He et al., 2005; Pedro and Ferreira, 2007; Peiris et al., 1998; Xie et al., 2008; Zhang et al., 2013).

For the SSC calibration model, the first 6 factors were used and $98.86 \%$ of the variance of the spectral variables was explained. The coefficient of determination for the calibration was $\mathrm{R}^{2}=0.88$, for the $\mathrm{CV}$ was $\mathrm{R}^{2}=0.77$. The RMSECV of the CV was $0.51^{\circ}$ Brix. The relationship between predicted and reference values of SSC are shown in Table 2 . The predictions for SSC are tightly aligned along the target line, where predicted and actual values are equal (Fig. 3). RMSECV of SSC Modell 0.51 Brix from nar- row region of VIS/NIR is higher than from NIR validated models (Ecarnot et al., 2013; He et al., 2005; Pedro and Ferreira, 2007; Peiris et al., 1998; Xie et al., 2008; Zhang et al., $2013)$. The accuracy of refractometer $\left( \pm 0.2^{\circ}\right.$ Brix $)$ increases further the error of predictive ability of the model. Many studies tried to investigate the potential of VIS/NIR spectroscopy for assessing internal quality parameters of tomato, mostly SSC (Peiris et al., 1998; Zhang et al., 2013). Moreover, many of the instruments used work in the transmittance mode, which requires greater light intensity and might damage vegetables by overheating (Long and Walsh, 2006).

In the Lycopene model, the first 7 factors were included, which explained the $99.06 \%$ variance of the reflectance values. The coefficient of determination for the calibration was $\mathrm{R}^{2}=0.91$, for the $\mathrm{CV}$ was $\mathrm{R}^{2}=0.75$ (Fig. 4). The RMSECV of the CV was $1.99 \mathrm{mg} / 100 \mathrm{~g}$. Till now there is no report which tried to create a predictive model for lycopene estimation from visible spectra. Although, lycopene content of tomato is well defined by non-destructively measured colour values of fruits, these methods are based on colorimetric determination, usually in CIELab colour system (Brandt et al., 2006; Stinco et al., 2013). Concentration of 

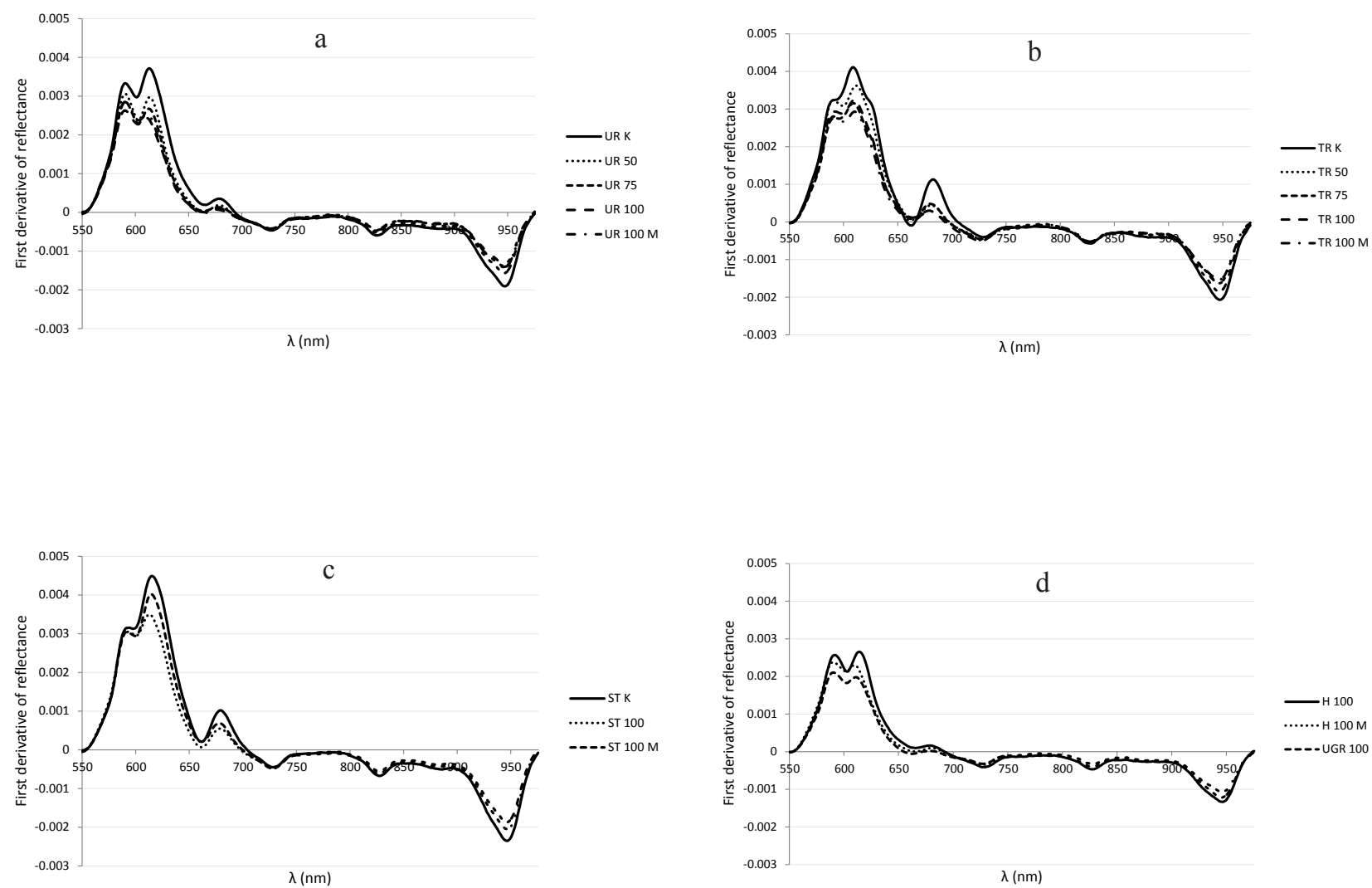

Fig. 2. Average VIS/NIR (550-975 nm) first derivative of reflectance spectra of tomato puree samples from different cultivar/treatment combinations $(n=4)$ : a - UR variants, $b-$ TR variants, $c-S T$ variants, $d-H$ and UGR variants.

T a b l e 2. Predictive capability of calibration models for SSC, lycopene and polyphenol content after S-G 1st derivative

\begin{tabular}{lccccccc}
\hline \multirow{2}{*}{$\begin{array}{l}\text { Quality } \\
\text { parameter }\end{array}$} & \multicolumn{2}{c}{ Calibration } & \multicolumn{2}{c}{ Cross-validation } & & \\
\cline { 2 - 7 } & $\mathrm{R}^{2}$ & RMSEC & $\mathrm{R}^{2}$ & RMSECV & $\begin{array}{c}\text { RMSECV } \\
(\%)\end{array}$ & Factors & $\begin{array}{c}\text { Explained } \\
\text { variance }\end{array}$ \\
\hline SCC & 0.88 & 0.39 & 0.77 & 0.51 & 6.6 & 6 & 98.86 \\
Lycopene & 0.91 & 1.27 & 0.75 & 1.99 & 7.6 & 7 & 99.06 \\
Polyphenols & 0.81 & 6.53 & 0.72 & 7.63 & 10.0 & 4 & 97.83 \\
\hline
\end{tabular}

lycopene is not homogeneous inside the fruits of traditional processing tomatoes, being the highest in the peel, lower in the fruit wall and placenta and the lowest in the seed (Toor and Savage, 2005), so methods based on surface measurements estimate well only the lycopene content of intact fruits. Recently bred tomatoes, with high and elevated lycopene content, require more accurate methods to quantify lycopene. Yellow $(570-590 \mathrm{~nm})$, orange $(590-620 \mathrm{~nm})$ and red $(620-750 \mathrm{~nm})$ region of reflectance spectra is correlated well with tomato fruit colour (Daood et al., 2014; Stinco et al., 2013). Reflectance spectra of about $600 \mathrm{~nm}$ represent the combination of yellow red coloration of fruits, which is more expressive by first derivative of spectra (Fig. 2).

For the polyphenol calibration model, only 4 factors were included, which explained the $97.83 \%$ of the measured explanatory variables. The coefficient of determination 


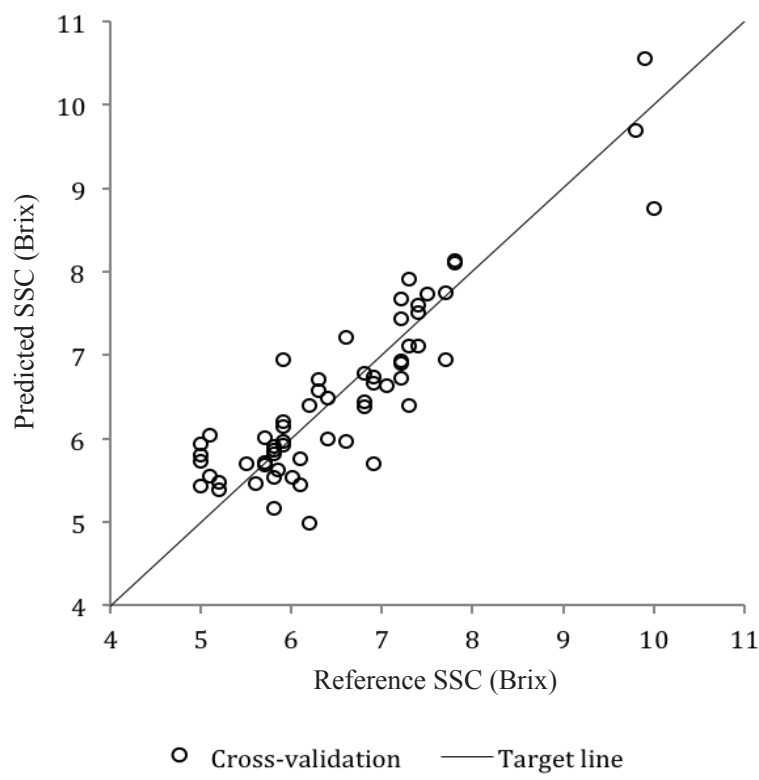

Fig. 3. Predicted versus reference values of SSC $(n=61)$.

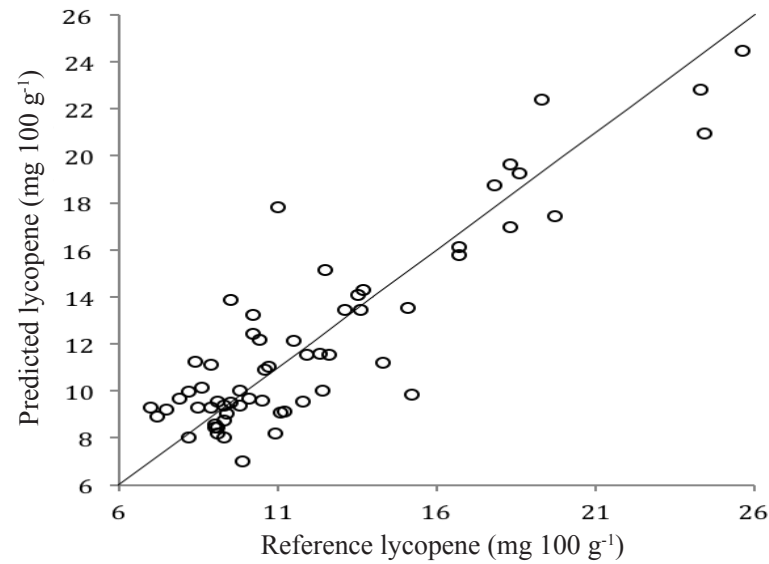

Fig. 4. Predicted versus reference values of lycopene concentration $(\mathrm{n}=61)$. Explanation as in Fig. 3.

for the calibration was $\mathrm{R}^{2}=0.81$, for the $\mathrm{CV}$ was $\mathrm{R}^{2}=0.72$ (Fig. 5) and the RMSECV was $7.63 \mathrm{mg} / 100 \mathrm{~g}$ (Table 2). RMSECV\% of polyphenols is the highest from the three modelled ingredients, due to the inaccuracy of the calibration model, which could result from the large number of phenolics. A total of 114 polyphenol compounds were detected in the tomato fruit, with the dominant phenolic acid being chlorogenic acid which presents $35-71 \%$ of total phenolics content (Pék et al., 2014; Slimestad and Verheul, 2009). There is no publication dealing with the spectroscopic prediction of polyphenols content of tomato.

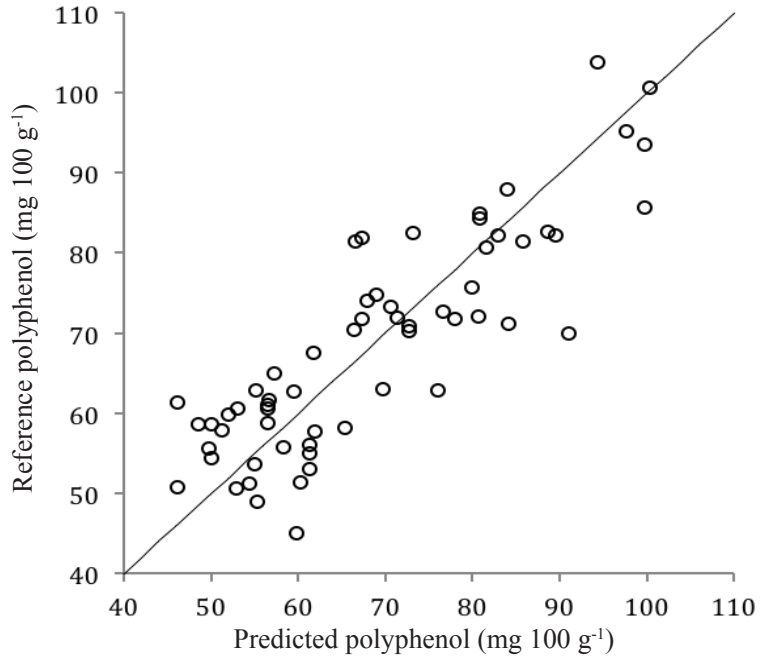

Fig. 5. Predicted versus reference values of polyphenol concentration $(n=61)$. Explanation as in Fig. 3.

\section{CONCLUSIONS}

1. Differences of VIS/NIR spectral reflectance among tomato varieties or irrigation treatments were significant, the higher the water supply the lower the reflectance spectra were in every variety. The treatment combinations could interfere with those differences.

2 . The food processing industry generally works with more homogenous raw materials produced by their licensed farmers working with the same cultivar, same plant cultivation technology and environmental conditions. Thus the concentration range of ingredients is narrower, so calibration models for these limited concentration values would have better prediction performance, with less error.

3. The three measured parameters have strong correlation with each other, so further reduction of RMSEP could be achieved by increasing the number of samples, or by using variety-specific models. Further development of the models could make them suitable for use by food processors.

4. The partial least squares regression models of the antioxidant components and soluble solids, with the 1st derivative of the tomato surface spectra as attributes, seem to satisfactorily explain majority of the measured instances.

\section{REFERENCES}

Abete I., Perez-Cornago A., Navas-Carretero S., Bondia-Pons I., Zulet M.A., and Martinez J.A., 2013. A regular lycopene 
enriched tomato sauce consumption influences antioxidant status of healthy young-subjects: A crossover study. J. Functional Foods, 5, 28-35.

Andersson M., 2009. A comparison of nine PLS1 algorithms. J. Chemometrics, 23, 518-529.

AOAC, 1990. Official Method of Analysis. Official Protocol 952.03. Association of Official Analytical Chemists, Arlington, VI, USA.

Beckles D.M., 2012. Factors affecting the postharvest soluble solids and sugar content of tomato (Solanum lycopersicum L.) fruit. Postharvest Biol. Technol., 63, 129-140.

Bolca S., Van de Wiele T., and Possemiers S., 2013. Gut metabotypes govern health effects of dietary polyphenols. Current Opinion Biotechnol., 24, 220-225.

Brandt S., Pék Z., Barna É., Lugasi A., and Helyes L., 2006. Lycopene content and colour of ripening tomatoes as affected by environmental conditions. J. Sci. Food Agric., 86, 568-572.

Canene-Adams K., Campbell J.K., Zaripheh S., Jeffery E.H., and Erdman Jr. J.W., 2005. The tomato as a functional food. J. Nutrition, 135, 1226-1230.

Daood H.G., Pék Z., Palotás G., Sidikov A., and Helyes L., 2014. Separation of carotenoids from tomatoes by HPLC using cross-linked C18 column and MS detection. J. Chromatographic Sci., (in press).

Ecarnot M., Baogonekczyk P., Tessarotto L., and. Chervin C., 2013. Rapid phenotyping of the tomato fruit model. MicroTom. withaportable VIS-NIR spectrometer. Plant Physiol. Biochemistry, 70, 159-163.

FAOSTAT, 2013. Production. Crops: Tomatoes. FAOSTAT Agricultural production database. http://faostat3.fao.org.

Figueirinha A., Paranhos A., Pérez-Alonso J.J., Santos-Buelga C., and Batista M.T., 2008. Cymbopogon citratus leaves: Characterization of flavonoids by HPLC-PDA-ESI/MS/MS and an approach to their potential as a source of bioactive polyphenols. Food Chemistry, 110, 718-728.

Gładyszewska B., Baranowski P., Mazurek W., Ciupak A., and Woźniak J., 2011. Radiation temperature of tomatoes and mechanical properties of their skin. Int. Agrophys., 25, 131-139.

Grandillo S., Zamir D., and Tanksley S.D., 1999. Genetic improvement of processing tomatoes: A 20 years perspective. Euphytica, 110, 85-97.

He Y., Zhang Y., Pereira A.G., Gómez A.H., and Wang J., 2005. Nondestructive Determination of Tomato Fruit Quality Characteristics Using Vis/NIR Spectroscopy Technique. International J. Information Technol., 11, 97-108.

Helyes L., Lugasi A., and Pék Z., 2006. Tomato fruit quality and content depend on stage of maturity. Hort Sci., 41, 1400-1401.

Helyes L., Lugasi A., and Pék Z., 2012. Effect of irrigation on processing tomato yield and antioxidant components. Turkish J. Agric. Forestry, 36, 702-709.

Hungarian Meteorological Service, Automatic Forecast of Hungarian Stations. <http://www.met.hu/idojaras/elorejelzes/magyarorszagi_telepulesek/index.php>
Long R.L. and Walsh K.B., 2006. Limitations to the measurement of intact melon total soluble solids using near infrared spectroscopy. Australian J. Agric. Res., 57, 403-410.

Lugasi A., Hóvári J., Bíró L., Brandt S., and Helyes L., 2004. Factors influencing lycopene content of foods. and lycopene intake of Hungarian population. Magyar Onkológia, 48, 131-136.

Merck index, 1989. Merck Press, Rahway, NJ, USA.

Pedro A.M.K. and Ferreira M.M.C., 2007. Simultaneously calibrating solids. sugars and acidity of tomato products using PLS2 and NIR spectroscopy. Analytica Chimica Acta, 595, 221-227.

Peiris K.H.S., Dull G.G., Leffler R.G., and Kays S.J., 1998. Near-infrared (NIR) spectrometric technique for nondestructive determination of soluble solids content in processing tomatoes. J. American Soci. Hort. Sci., 123, 1089-1093.

Pék Z., Szuvandzsiev P., Daood H., Neményi A., and Helyes L., 2014. Effect of irrigation on yield parameters and antioxidant profiles of processing cherry tomato. Central European J. Biol., 9, 383-395.

Sadler G., Davies J., and Dezman D., 1990. Rapid extraction of lycopene and beta-carotene from reconstituted tomato paste and pink grapefruit homogenates. J. Food Sci., 55, 1460-1461.

Singh R.P., Carroad P.A., Chinnan M.S., Rose W.W., and Jacob N.L., 1980. Energy accounting in canning tomato products. J. Food Sci., 45, 735-739.

Slimestad R. and Verheul M., 2009. Review of flavonoids and other phenolics from fruits of different tomato (Lycopersicon esculentum Mill.) cultivars. J. Sci. Food Agric., 89, 1255-1270.

Stinco C.M., Rodríguez-Pulido F.J., Escudero-Gilete M.L., Gordillo B., Vicario. I.M., and Meléndez-Martínez A.J., 2013. Lycopene isomers in fresh and processed tomato products: Correlations with instrumental color measurements by digital image analysis and spectroradiometry. Food Res. Int., 50, 111-120.

Toor R.K. and Savage G.P., 2005. Antioxidant activity in different fractions of tomatoes. Food Res. Int., 38, 487-494.

Wold S., Michael S., and Eriksson L., 2001. PLS-regression: a basic tool of chemometrics. Chemometrics Intelligent Laboratory Sys., 58, 109-130.

World Health Organization, 1990. Dietary nutrition and the prevention of chronic diseases. Report of a WHO Study Group. WHO Technical Report, 916, 148.

Xie L., Ying Y., Lin H., Zhou Y., and Niu X., 2008. Nondestructive determination of soluble solids content and $\mathrm{pH}$ in tomato juice using NIR transmittance spectroscopy. Sensing and Instrumentation Food Quality Safety, 2, 111-115.

Zhang R., Rao X., Gao Y., Hu D., and Ying Y., 2013. Inspection of soluble solid content for tomatoes in different positions based on hyperspectral diffuse transmittance imaging. Trans. Chinese Soc. Agric. Eng., 29, 247-252. 